\title{
IMPACTO DE LA GLOBALIZACION EN LAS SOCIEDADES LATINOAMERICANAS ¿QUE HACER FRENTE A ELLO?
}

Jacques Chonchol*

Vivimos en un mundo que está cambiando muy rápidamente y de una manera tan compleja que es difícil discernir cuales son los cambios más significativos y los que tendrán mayor influencia en la sociedad del mañana. Aunque existen evidentemente ciertas coincidencias en los análisis del presente y sobre sus perspectivas para el futuro, hay frente a la importancia de los diferentes factores apreciaciones divergentes. Conviene sin embargo no olvidar, a este respecto, que los caminos de la historia pueden ser muy diversos y casi imposible de preveer ¿Quién predecía, por ejemplo, a comienzos de los años 80 el desmoronamiento interno del bloque socialista que se produjo como consecuencia de esse proceso de reestructuración y de reorganización llamado "Perestroika" que inició Gorbachov en 1985? ¿Y quién podía predecir todas la consecuencias que ello acarreó no sólo para los ex-países socialistas sino también para el resto del mundo?

Si seguimos a Paul Kennedy y sus excelentes reflexiones sobre las perspectivas del siglo $\mathrm{XXI}^{1}$, las grandes tendencias de la sociedad contemporánea que se destacan más son las siguientes:
a) La explosión demográfica aún en expansión, el 95\% de la cual se con-

(1) Paul Kennedy "Preparing The XXI st Century", Harper Collins Publishers, 1993. centra en los países en desarrollo, y el aumento rápido de una población que no podrá ser sustentada según los modos y niveles actuales de consumo de los recursos naturales.

b) La revolución de las finanzas y de las comunicaciones que ha llevado a una rápida internacionalización de las economías y al rol dominante de las sociedades multinacionales en el contexto de esta nueva economia.

c) La disminución de las tierras agrícolas como consecuencia de la extensión de tierras arables ocupadas por ciudades, caminos e infraestructuras, así como por los procesos de erosión, degradación y desertificación de muchas de las tierras que se usaban anteriormente. Este hecho se observa simultáneamente con la necesidad de aumentar la productividad de las tierras aún disponibles para evitar que la malnutrición y el hambre aumenten. Al mismo tiempo observamos las posibilidades que ofrece la revolución bio-tecnológica para esta finalidad de aumentar la productividad de las tierras utilizadas. 
d) La nueva revolución industrial que significa la robótica y la automatización y las consecuencias de este fenómeno en la situación y condiciones del empleo de la fuerza de trabajo.

e) Las amenazas contra el medio natural que significan las nuevas formas de vida y de producción, particularmente en los países desarrollados y sus efectos de imitación en los países en desarrollo y

f) La erosión del poder de los Estados Nacionales sin haberse aún encontrado un sistema político de sustitución apropiado para enfrentar los grandes desafíos del futuro.

Si seguimos por outra parte al conjunto de grandes especialistas de la ciencia, de la geopolítica y de la cultura reunidos por el proyecto LEO$\mathrm{NARDO}^{2}$, podemos destacar, entre otras, las siguientes tendencias: los fuertes impulsos hacia el fundamentalismo religioso, la mestización masiva de la humanidad en lo étnico y en lo cultural, la apertura hacia el espacio que rodea el planeta tierra el que constituye ya la nueva frontera, en lo científico, lo industrial y lo económico; la urbanización hacia las grandes metrópolis, el impacto de la producción en el medio ambiente, la desmaterialización creciente de la economia, la existencia de largos periodos de desequilibrio que están conduciendo a movimientos masivos

(2) "LEONARDO": Publicación conjunta y simultánea de 4 grandes periódicos europeos, como son “EL PAIS", "LE MONDE”, “LA REPUBLICA", “THE INDEPENDENT”, con motivo de la exposición universal de Sevilla de 1992. de población, el proceso de integración y de enriquecimiento global junto con una distribuición extraordinariamente desigual de la riqueza y de los ingresos; la internacionalización creciente de las ciencias, de las tecnologias y de los sistemas productivos con sus aspectos positivos y negativos y la relocalización y nueva distribución de los centro de poder y de decisión.

En relación con todos estos cambios que estamos viviendo dia a dia, con diferentes grados de intensidad y de conciencia, se ha hecho usual hablar del proceso de globalización a que estamos sometidos. Si bien esto es evidente en muchos aspectos de nuestras sociedades, particularmente en lo que se refiere a la rapidez de difusión de las informaciones y de ciertas tecnologias asi como en la internacionalización de las finanzas y de los sistemas de comunicación y de transportes, lo es mucho menos en otros aspectos como la difusión de la cultura, de los niveles de conocimiento y de la igualdad de oportunidades.

A fin de tratar de aclarar las formas de esta globalización y sus efectos sociales examinaremos las principales tendencias en las transformaciones institucionales, siguiendo para ello en gran parte las reflexiones de la UNRISD ${ }^{3}$, pero también de otros especialistas. Estas tendencias son:

(3) UNRISD, Instituto de Investigaciones de las Naciones Unidas para el Desarrollo Social, ver su publicación "Estados de Desorden: Los Efectos Sociales de la Globalización", Ginebra 1995. 
1. La expansión de la democracia liberal.

2. El domínio que ejercen las fuerzas de mercado.

3. La terciarización de la economia.

4. La integración de la economía global.

5. La transformación de los sistemas de producción y los mercados de trabajo.

6. La velocidad del cambio tecnológico y

7. La revolución en los medios de comu nicación de masas y el consumismo.

En apariencia estas transformaciones son neutras y en parte independientes las unas de las otras, pero en la realidad cada una tiene sus ramificiones sociales complejas que benefician a algunos grupos y a otros les imponen privaciones y dificultades.

\section{La expansión de la democracia liberal}

El comunismo se ha derrumbado completamente en la Europa Oriental y en la antigua Unión Soviética y en muchos otros países los sistemas multipartidistas han reemplazado a los regimenes autoritarios de partido único o dominados por los militares.

La búsqueda de la libertad y el pluralismo no se reduce sólo a lo político. También se expresa en lo económico, pero esta libertad económica llevada a un extremo y sin instituciones que resguarden el interés colectivo de la sociedad y el bien común, lleva a profundas desigualdades, ya que mientras unos acumulan poder y riquezas otros no tienen con que satisfacer sus necesidades esenciales. Por outro lado, un libertad económica sin resguardo abre paso a todo tipo de corrupciones y al tráfico de productos como drogas y armas, lo que atenta contra las necesidades de la sociedad.
La expansión de la democracia en la medida en que no es sólo formal da paso a una participación mayor de los distintos grupos sociales en la resolución de sus problemas y posibilita la existencia de una sociedad civil más poderosa por el peso de la opinión pública internacional. Las organizaciones de la sociedad civil pueden ampliar y profundizar los lazos de solidaridad de la ciudadanía mundial, pero también pueden convertirse en focos de rivalidades tradicionales y crear nuevos antagonismos étnicos o divisiones territoriales.

\section{El domínio de las fuerzas de mercado}

Los giros hacia la democracia y la libertad han de estar acompañados o precedidos de cambios económicos significativos, debiendo mencionarse entre ellos, particularmente, la importancia que han adquirido a nivel mundial las fuerzas del mercado y de la empresa privada. Este resurgimiento del liberalismo económico tuvo su origen en los países industrializados, particularmente en el Reino Unido y en los Estados Unidos, que se embarcaron en los años ochenta en una serie de reformas radicales tendientes a reducir la intervención del Estado en la economía, privatizar las empresas públicas, liberalizar los precios, eliminar los reglamentos en torno a los servicios básicos, controlar la inflación y abrir sus economías.

Este proceso de cambio que se ha denominado "ajuste estructural", se inició como dijimos en los países industrializados, pero desde entonces se ha extendido por todo el mundo. A nivel internacional el auge de las fuerzas de mercado ha fortalecido considerablemente el poder de los inversionistas internacionales y de los países acreedores, así como el de las instituciones financeiras más importantes, el Fondo Monetario 
Internacional (FMI) y el Banco Mundial. Al mismo tiempo y consiguientemente se ha debilitado la posición de los países que dependen fundamentalmente del capital extranjero o de la ayuda externa. También se han producido cambios profundos al interior de los países: los proprietarios del capital junto com algunos grupos de administradores y ejecutivos profesionales han adquirido mayor poder, en tanto que la clase trabajadora organizada lo ha perdido.

Outro efecto de la liberalización económica ha sido el desencadenamiento de una competencia feroz tanto al interior de las naciones como entre ellas mismas. Esta situación ha aumentado a menudo la eficiencia de la producción, pero también ha abatido los salários y a hecho que aumenten el desempleo y la pobreza. Por outra parte la gente más pobre ha visto sus problemas agravarse por la retirada sistemática del Estado de la economía, el cual ha ido reduciendo constantemente los subsidios concedidos anteriormente a bienes básicos, tales como los alimentos y el transporte, a la vez que ha recortado los servicios de bienestar social.

\section{La terciarización de la economía}

En la actualidad presenciamos una transformación que abarca todos los ámbitos de la vida, lo que algunos llaman el tránsito de la sociedad industrial moderna a la sociedad postmoderna, suministradora de servicios. Este proceso puede describirse como terciarización, como la desvinculación de la economia de su substancia material, lo que se denomina la desmaterialización ${ }^{4}$.

(4) ULRICHMENZEL “La Revolución Post-Industrial” Revista D+C, 5/95, Revista de Desarrollo y Cooperación publicada en la República Alemana (Frankfurt, Alemania). Para los párrafos siguientes no hemos basado fundamentalmente en este texto.
Este proceso tiene consecuencias tanto para los países industriales como para los países en desarrollo. En los países industriales el aporte de la producción primaria de la agricultura y la minería se ubicaba al comienzo de la Revolución Industrial en cerca del 80\%. Com el avance de la industrialización se ubicó entre 1850 y 1900 por debajo del nivel del $40 \%$ y hoy se mueve en alrededor del $2 \%$, a pesar de que naturalmente la producción agrícola ha aumentado en forma considerable en términos absolutos. Paralelamente el sector secundario, el de transformación de los productos primarios en secundario, el de transformación de los productos primarios en mercancías elaboradas y semi elaboradas aumentó de cerca de 10\% (artesanía e industria casera tradicional) a cerca de $50 \%$ entre fines del siglo XIX y comienzos del $X X$. Desde entonces esta proporción se ha venido reduciendo hasta un $15 \%$ a $30 \%$, pese a la creciente produccíon industrial. Al mismo tiempo el sector terciario, el de los servicios, ha incrementado su importancia y no solamente crece en términos absolutos sino relativos, alcanzando hoy un volumen de 60 a 70\%.

En este sector terciario los componentes principales son los siguientes:

i) Comercio mayorista y minorista, rama hotelera y gastronómica.

ii) Transporte, almacenamiento y comunicaciones

iii) Sistema financiero, seguros, sector inmobiliario y servicios profesionales.

iv) Servicios personales y sociales

v) Servicios públicos

4. La integración de la economía en escala global

Junto com la expansión de la democracia liberal, la significación creciente en el sistema 
económico de las fuerzas de mercado y la terciarización de la economía, se ha venido produciendo una integración acelerada de la economia mundial. El aspecto más destacado de esta integración es la movilidad del capital. El sistema computarizado de negocios hace girar enormes sumas de dinero por encima de las fronteras nacionales. El crecimiento de un mercado mundial de capitales y de servicios financieros escapa completamente al control de los gobiernos y de los Bancos Centrales. Se estima en más de mil doscientos billones de dólares el volumen de los movimientos de capital que circulan permanentemente según las variaciones de los tipos de cambios, lo que es el terreno de una especulación financiera sin límites.

La mundialización del capital ha acelerado la internacionalización de las inversiones y en consecuencia del sistema productivo, al mismo tiempo que se integran por grandes regiones los flujos comerciales. A su vez por la vía del crecimiento externo se ha estimulado la mundialización de las empresas, de las estrategias y de los mercados: inversiones directas en el extranjero, deslocalizaciones, fusiones, alianzas entre empresas. Asi cada grupo industrial o financiero importante persigue hoy día una estrategia en todas las regiones del mundo. Por outra parte, la necesidad de las empresas en proceso de internacionalización de tener acceso fácil al mercado financiero mundial ha amplificado la capitalización bursátil. La tendencia dominante es la multinacionalización de los accionistas. Al mismo tiempo los grupos industriales se han convertido en grupos financieros y deciden y arbitran permanentemente entre los capitales comprometidos en las diferentes actividades de sus filiales.

Los actores prodominantes de esta integración económica son las empresas transnacionales. Las 37 mil matrices de empresas transnacionales com mas de 200 mil filiales por todo el mundo controlan casi el $75 \%$ de todo el comercio mundial de mercancías, productos manufacturados y servicios. Una tercera parte de este comercio se realiza al interior de las empresas haciendo que sea muy difícil para los gobiernos y para los organismos de comercio internacional ejercer sobre ellas cualquier tipo de control. En estas circunstancias es menos probable que la liberalización del comercio genere mercados libres y competitivos, y en cambio es más probable, que de como resultado una competencia administrada.

La integración de la economía mundial es muy positiva para aquellos países suficientemente poderosos como para aprovechar las oportunidades que ofrece el crecimiento acelerado, pero funciona en detrimento de los países y regiones más débiles, los cuales frente a una competencia dura son vulnerables a las fuerzas del capital.

Dentro de este proceso de integración de la economía a escala mundial lo más significativo ha sido, en estos últimos 10 años, el crecimiento explosivo del sistema financeiro internacional.

Durante siglos la economía internacional consistió en primer lugar en la exportación y importación de mercancías. Los servicios en cambio no eran exportables pues quedaban ligados a su lugar de origen. Si mostraban una dimensión internacional, como el transporte, los seguros o los créditos, siempre se vinculaban al comercio de mercancías y operaban para facilitarlo.

Pero dos causas motivaron desde mediados de los años 80 un cambio estructural cualitativo en la economía mundial. Por una parte las innovaciones revolucionarias en el área de la microeletrónica y de las telecomunicaciones. La creación de redes globales fue técnicamente posible y ahora es una realidad, en especial la incorporación de bolsas comerciales. Esto facilitó eliminar el enraizamiento local de los servicios y 
hacerlos operables a nivel internacional. Por outra parte los extraordinarios desequilibrios observados desde los años 80 en las balanzas comerciales de los grandes países de la economía mundial exigió para su equilibrio la importación y exportación de capitales. Los elevados excedentes en la balanza comercial por parte de Japón, la Republica Federal Alemana y algunos países de la OPEP arrojaron capitales gigantescos que buscaron posibilidades rentables de colocación y las encontraron en países com grandes déficits como los Estados Unidos o Gran Bretaña.

Outra transformación significativa que se ha producido es en la naturaleza de las empresas productivas.

\section{La transformación de los sistemas de producción y de los mercados de trabajo}

Las empresas más dinámicas en este mercado cada vez más integrado tienden a utilizar unidades de producción más pequeñas, más flexibles y autónomas, más especializadas en ciertas funciones específicas y subcontratar gran parte del trabajo que deben realizar con otras empresas. Para los trabajadores o empleados en los sectores de alta tecnología, especialmente en los países industrializados, este cambio puede significar mejores condiciones de trabajo y de ingreso. Pero también les permite a muchas empresas mayores renunciar a sus obligaciones sociales con su fuerza de trabajo, además de traspasarle el riesgo económico a empresas más pequeñas. Esta especialización flexible permite una respuesta más rápida a las condiciones cambiantes del mercado, pero también origina un ámbito extremadamente precario para muchas de las empresas subcontratadas y para muchos de los trabajadores.
Igualmente negativo es el hecho de que estos métodos de trabajo han debilitado la relación entre la expansión del producto y el crecimiento del empleo dando por resultado un crecimiento sin o con escasa oferta de empleo. Por ello, aún cuando se pase de una situación de recesión a un período de gran crecimiento, la oferta de empleo puede no aumentar significativamente.

Este ámbito más flexible de utilización de la mano de obra implica también una tendencia hacia el empleo a tiempo parcial e inseguro, tendencia que está aumentando aún en los países desarrollados. En Gran Bretaña por ejemplo el $20 \%$ del total de la población ahora ocupada trabaja a tiempo parcial y en Francia, Alemania, Holanda, Luxemburgo y España, la mitad o más de la oferta de empleo generada en el decenio de los ochenta era para los trabajadores contratados a tiempo parcial. Muchos de estes nuevos empleos precarios están siendo ocupados por mujeres quienes cada vez más desean o necesitan trabajar fuera del hogar. En los países industrializados las mujeres constituyen actualmente entre el $40 \%$ y $50 \%$ de la fuerza laboral y trabajan con más facilidad a tiempo parcial y por salarios inferiores.En Europa el pago a las mujeres en empleos no agrícolas representa solamente entre el $70 \%$ y el $80 \%$ de lo que se paga a los hombres y en el Japón el 50\%.

En Estados Unidos, así como en otros países industrializados, como muy bien lo ha señalado Robert Reich, el ex ministro de trabajo del presidente Clinton ${ }^{5}$, tres grandes categorías de empleos se observan: los de los servicios de producción corriente, los servicios personales y los servicios de "los manipuladores de símbolos".

(5) Ver su obra "The Work of Nations", New York, 1991. 
Los primeros corresponden a los de los trabajadores corrientes que trabajan en fábricas junto con otros de su misma categoria. Son dirigidos en suas actividades por procedimientos standards y reglas codificadas, sus supervisores son a su vez controlados por otros supervisores que los controlan con computadoras. Los salarios de los trabajadores corrientes varian en función de su tiempoy cantidad de trabajo. En 1990 representaban la cuarta parte de los empleos norteamericanos y su proporción tiende a declinar.

Los de servicios personales, la segunda categoria de trabajadores implican también tareas repetitivas y simples: empleados de comercio, de hoteles, de agencias inmobiliarias, servidores de restoranes, cajeros, secretarias, enfermeras, mecánicos y servicios de todo tipo. Su salario es también función del número de horas y de la cantidad de trabajo realizada. En 1990 los servicios personales representaban un $30 \%$ de los empleos y su proporción aumenta rápidamente.

Los servicios de los "manipuladores de símbolos" la tercera categoría de ocupaciones, incluyen todas las actividades de identificación y resolución de problemas y de intermediación estratégica. En esta categoria se clasifican los investigadores, ingenieros, informáticos, abogados de firmas, consejeros financieros o fiscales, especialistas de organización publicistas, encargados de mercado, etc. El conjunto de los manipuladores de símbolos no constituyen sino el $20 \%$ de los empleos norteamericanos en 1990.

Las tres categorias cubren 3 de cada cuatro empleos en los Estados Unidos. El cuarto restante está representado por los agricultores, empleados públicos y otras categorías cuyos ingresos están protegidos por el Estado de los efectos de la competencia internacional.

Entre las tres categorías examinadas la diferencia de los ingresos han estado aumentando.
Mientras los ingresos de los primeros y segundos bajan o se mantiene en términos relativos y absolutos, los de los terceros aumentan considerablemente y las diferencias se hacen cada vez mayores.

En lo que respecta a los países en desarrollo la transformación de los sistemas de producción se refleja en el hecho de que el sector informal y precario está en todas partes en rápido crecimiento. La mayor flexibilidad, menores remuneraciones de este sector, así como su capacidad para adaptarse a la baja de los costos de producción parece estar en consonancia com el modelo económico actual. En muchos países en desarrollo el sector informal está absorbiendo ahora el $60 \%$ o más de la fuerza de trabajo urbana. No obstante que las empresas informales pueden parecer muy dinámicas, muchas veces sólo sirven como último recurso para conseguir empleo, lo cual significa que constituyen un refugio para el ejército de reserva de los desempleados.

\section{La velocidad del cambio tecnológico}

La fuerza propulsora de la mayoria de estos nuevos sistema de producción se encuentra en el ritmo acelerado del progreso tecnológico, sobre todo en los campos de la electrónica, las comunicaciones y el transporte.

El progreso tecnológico en las teleconunicaciones ha dado por resultado la reducción significativa de sus costos. La tecnologia de los computadores está transformando la velocidade y la índole de las comunicaciones.

En el sector manufacturero ha habido avances semejantes impulsados por los computadores. Entre 1982 y 1992 el número de robots industriales en uso en el mundo aumentó en más de 10 veces. El transporte también se ha transformado, sobre todo en los viajes aéreos: entre 1960 
y 1990 los costos de operación por milla de las aerolíneas a escala mundial se redujeron en más de un $60 \%$. Casi una cuarta parte de las exportaciones de manufacturas a nivel internacional corresponden a las que ahora se envían por vía aérea.

Estos hechos han tenido repercusiones económicas y sociales enormes, transformado las relaciones de trabajo, suprimiendo empleos en algunas partes y creando otros en otros lugares. Ahora por ejemplo muchas empresas pueden generar empleos en países lejanos sobre procesamiento de datos, empleos que son muy intensivos en el uso de la mano de obra y que es conveniente para ellas realizar donde su costo es inferior.

7. La revolución en los medios de comunicación de masas y el consumismo

Uno de los efectos más notables de las nuevas tecnologías de comunicaciones es el ímpetu que se le ha dado al desarrollo de los servicios de informaciones y noticias a nivel mundial. La palabra escrita y la prensa están siendo transformados por la computación, pero los desarrollos verdaderamente revolucionarios han tenido lugar en la televisión y en el sistema de video. Actualmente hay más de mil doscientos millones de aparatos de televisión en uso por el mundo.

La televisión puede ayudar a difundir el conocimiento y la comprensión y donde la gente produce sus propios programas puede favorecer y apoyar el fortalecimiento de la cultura y de los idiomas locales. Pero también permite un proceso de imperialismo cultural por parte de los medios de comunicación con un número muy reducido de países que producen programas que se transmiten por todo el mundo. Los Estados Uni- dos exportan más de 120 mil horas anuales de programación televisiva tan sólo a Europa y el comercio mundial de la programación está creciendo a una tasa de más de $15 \%$ anual. En muchos países el potencial de la televisión para promover el consumismo y erosionar los valores tradicionales ha creado una fuerte resistencia.

La habilidad para transmitir informes instantáneamente desde los discos de satélites también repercute de manera significativa en la cobertura de las noticias, no sólo incrementando la variedad y la velocidad de los flujos de información, sino también modificando el curso de los acontecimientos.

\section{EL COSTO POLITICO DE LA GLOBALIZACION}

Aparentemente estos procesos que acabamos de describir operan independientemente unos de otros y son parte de la marcha inevitable del progreso humano. Pero en la realidad son interdependientes y están conformados por fuerzas políticas poderosas las que determinan quiénes se benefician y quiénes se perjudican. De todas estas fuerzas los principales beneficiarios han sido el gobierno de los Estados Unidos y los grandes capitalistas de ese país y del sistema internacional.

La nueva estratégia económica de dicho gobierno se hizo sentir después de 1981 cuando la administración del Presidente Reagan redujo los impuestos directos al ingreso, a los intereses y a las ganancias transfiriendo más carga a los impuestos indirectos para atraer inversiones de capitales. Del mismo modo cortó los gastos de previsión y los gastos sociales. Esto se impuso como el modelo que todos debían seguir.

En casi todas parte, los gobiernos, independientemente de su posición política, respondieron del mismo modo: cortando las previsiones y los gastos 
sociales, privatizando las empresas públicas y tratando de que el gobierno funcionase más como una "empresa privada" orientada hacia el mercado.

Tanto los gobiernos como las empresas también fueron afectados profundamente por la globalización de las finanzas internacionales.

Los gobiernos que se endeudan con los mercados financieros internacionales tienen que mantener calificaciones favorables sobre riesgo y solvencia, por lo que llegan a depender crecientemente de la disciplina de las fuerzas del mercado internacional y se vuelven muy sensibles a los pronunciamientos de las agencias que califican la confiabilidad de los bonos. Los operadores del mercado escudriñan constantemente las políticas de los gobiernos, especialmente aquellas que pudieran afectar las tasas de retorno del capital (como la tasa de inflación y el riesgo que el gobierno deje de cumplir sus compromisos) y pueden responder rápidamente transfiriendo grandes cantidades de capital líquido por todo el mundo. Los grandes inversionistas institucionales como los fondos de pensiones y las compañias de seguros, así como las tesorerías de empresas, se mantienen en alerta constante para reducir los riesgos al mínimo y maximizar las ganancias.

Estos flujos han erosionado constantemente la autonomía nacional. Anteriormente; las fronteras nacionales correspondían casi completamente com los límites de la autoridad política y la actividad económica y el comercio internacional servían como lazo principal entre las naciones autónomas. Ahora se tiene una economía global más integrada, en la cual no solamente el intercambio sino también la producción y el financiamiento están organizados y articulados a una escala planetaria.

Esto no sólo ha constituido un capitalismo mundial, sino que también ha contribuido a reestructurar el Estado. En forma desigual, pero acumulativa, los Estados-Nacionales han tenido que adaptarse a las fuerzas económicas internacionales y en muchos casos han tenido que subordinarse a ellas. Los gobiernos responden a estas nuevas condiciones convergiendo hacia lo que se ha llamado el "Estado de la competencia".

Este nuevo sistema financeiro global opera fuera del control de cualquier gobierno y crecientemente establece su propia agenda trabajando sistemáticamente en favor de los intereses de los operadores financieros, y en oposición a los de los fabricantes, productores o de los planificadores gubernamentales, enfatizando además el corto plazo en vez del largo plazo. Las economías nacionales se han desligado cada vez más de los procesos sociales. La nueva ley es la ley de la selva, sólo el más apto puede sobrevivir.

Este nuevo ambiente para las finanzas y el comercio internacional ha coincidido hasta cierto punto com un mayor multilateralismo de la política económica, ligando a los gobiernos de los países desarrollados y a los organismos internacionales como el FMI y el Banco Mundial. El desarrollo de estas instituciones financieras fue influido, preferentemente por la crisis de endeudamiento de principios del decenio de los 80 . Los Estados Unidos junto al FMI y el Banco Mundial encabezaban una coalición compleja de los principales intereses acreedores procedentes principalmente del Grupo de los Siete.

Todos estos países ricos y los organismos internacionales representan hoy un conjunto de fuerzas políticas y sociales que están tratando de lograr algún consenso internacional sobre los componentes esenciales de la cooperación internacional. Esto implica un cambio en el tipo de Estado nacional que se desea siguiendo los lineamentos neo-liberales, com menos intervención por parte de los gobiernos y los servicios relacionados con el bienestar social menos generoso. A 
la vez se pretende darle mayor peso a economistas, administradores financieros y oficiales de los bancos centrales, tecnócratas neo-clásicos, quienes creen que dejándole rienda suelta a las fuerzas del mercado se producirá el mejor resultado y quienes tienden a pensar de la misma forma en lo que se refiere a los asuntos de la cooperación económica internacional.

Antes de 1982 la expresión "ajuste estructural" no significaba nada para la mayoría de los funcionarios ni para los científicos sociales, pero a finales de esse mismo decenio era una expresión muy común en la mayoria de los países en desarrollo. Los programas de ajustes estructurales son utilizados como método principal para promover la aplicación de los modelos de desarrollo neoliberales en los países endeudados del Tercer mundo.

Los países en desarrollo quedaron en una situación particularmente vulnerable por el endeudamiento masivo em que se vieron envueltos durante los años 70 y principios de los 80 . Esa situación aumentó el poder de los países acreedores notablemente los Estados Unidos y el Reino Unido, justo cuando en éstos últimos se iniciaba el predomínio de políticas que adoptaban las ideas del libre mercado, convergencia desafortunada que permitió que los puntos de vistas neo-liberales sobre el ajuste estructural dominaran el debate sobre el desarrollo en los años 80 . Sin las crisis de la deuda los economistas neoliberales no habrían tenido tanta mano libre en los países en desarrollo. Además si los gobiernos de Reagan y de la Thatcher no hubieran durado tanto tiempo, probablemente se habría tratado de solucionar la crisis de la deuda de una forma mucho menos recesiva.

Como consecuencia de todo esto el "ajuste estructural" no es algo neutro sino un experimento radical de la economía neo-liberal y los gobiernos de los países en desarrollo quedaron sometidos a un apremio intenso para que abandonaran sus proyectos nacionales de desarrollo económico y arriesgaran el futuro de sus pueblos participando sin protección alguna en los mercados internacionales.

Los donantes y las instituciones financieras internacionales además de medidas de estabilización tradicionales como reducir los déficit presupuestarios, limitar el monto del dinero en circulación para reducir la inflación, aumentar el incentivo para las exportaciones y recucir las importaciones, aplicar políticas económicas deflacionarias incluyendo lad restricción de los salarios, fijar la tasa de cambio a un nivel adecuado, exigieron reformas en los siguientes campos:

a) Reducir drásticamente las barreras al comercio exterior exponiendo a los productores locales a la competencia con los productores extranjeros.

b) Reducir o abolir los subsidios y los controles de precios, a fin de eliminar las llamadas "distorsiones" a los precios locales de bienes y servicio.

c) Retirar los controles sobre los movimientos de capital.

d) Privatizar las empresas del Estado.

e) Favorecer la inversión privada extranjera retirándole los controles existentes.

f) Reducir al mínimo la intervención estatal no sólo en la administración de la economía sino también a la dotación de los servicios sociales.

Los asessores neo-liberales se imaginaban un país ideal en el cual la economía seria autorre- 
gulada en su mayor parte a través de la competencia abierta entre firmas privadas; y su sector público seria relativamente pasivo, proporcionando un mínimo de servicios necesarios para conducir eficientemente los negocios privados y para proteger a los miembros más débiles de la sociedad. Desafortunadamente para ellos esa imagen no correspondía a la realidad en ningún lugar del mundo ya fuera en los países industrializados del Norte o en los países en desarrollo. La mayoria de los países industrializados tenían Estados intervencionistas que protegian a los grupos de intereses locales bastante más de lo que el modelo ideal neo-liberal lo permitia (aún allí donde los paladines de este modelo económico habían tenido a su cargo los programas de reformas durante muchos años). Además los países en desarrollo que habían aplicado com éxito programas de ajustes orientados hacia la exportación, tales como la República de Corea y Singapur tenían Estados fuertes y sectores privados sumamente oligopólicos.

No obstante eso, en muchas ocasiones los organismos internacionales trataron de imponer de manera rígida sus recomendaciones de política a sociedades que eran muy complejas y diversas. El Banco Mundial dedicó una proporción creciente de sus fondos a préstamos condicionados a que se aplicara el ajuste estructural, y muchos otros organismos de desarrollo y donantes bilaterales también condicionaron su ayuda a que los gobiernos receptores de esta últim aceptaran la agenda neo-liberal. Esta red cada vez más estricta de "condicionalidad cruzada" les dio a los patrocinadores de la ayuda internacional una influencia sin precedentes en el diseño tanto de la política macroeconómica como de la social de los países en desarrollo.

\section{EL COSTO SOCIAL DE LA RECESION Y LA REESTRUCTURACION}

Las políticas de ajuste han ocasionado en los países deficitarios una situación de recesión, puesto que los gobiernos han restringido la demanda, recortando o reduciendo los salarios y disminuyendo los gastos públicos. Por otro lado al fomentar el alza de las tasas de interés se ha reducido la inversión y se han restringido las nuevas oportunidades de empleo. Por lo tanto la estabilización y el ajuste han implicado penurias para la población en general. Anteriormente los gobiernos podían justificar estos sacrificios alegando que sólo serían temporales y que las correcciones al curso de la economía en un momento dado se traducirían en una prosperidad mayor. Pero desde principios del 80 la situación ha cambiado. Las condiciones económicas y globales no han permitido que se recuperaram se han aplicado políticas deflacionarias para tratar de manejar la crisis económica. Al mismo tiempo sus pueblos han tenido que soportar el trastorno social que se deriva de la reorganización radical de la economía para orientarla hacia el mercado libre. La mayoría de la población en los países sumamente endeudados de Africa y America Latina sufren una drástica caída en sus niveles de vida. Entre 1980 y 1990 sus ingresos per capita disminuyeron marcadamente y para la gente más pobre la caída fue aún más estrepitosa, con salarios mínimos rebajándose a menudo de 50\% o más. Mucha gente del sector formal perdió sus empleos y tuvo que buscar trabajo en condiciones más precarias y mal pagadas en el sector informal. La población también se perjudicó por los recortes en los servicios del sector público.

Los partidarios del ajuste justificaron los recortes en los servicios públicos, el incremento en el desempleo y la aguzación de la pobreza, alegando que eran productos colaterales de la mo- 
dernización económica, tan penosos como inevitables. Ellos esperaban que hubiera un costo social de corto plazo contra las ganancias económicas de largo plazo.Pero lo que no previeron fue que las repercusiones sociales por si mismas podrían frustrar los efectos económicos deseados.

La teoría económica neoliberal supone por ejemplo, que un mercado no regulado dará por resultado mayor eficiencia y equidad. Com esto se ignora el hecho de que algunos individuos no necesariamente pueden estar, tratando de maximizar sus propios intereses económicos. Supone también que todos tienen acceso a la información precisa y al día sobre los precios y sobre oportunidades que pueda ofrecer el mercado pero en la mayoria de los casos eso no es lo que sucede.

En general la teoría reduce al mínimo el papel de la organización y de las instituciones sociales en la conformación de los resultados económicos, así como el balance de poder entre los que ganan y los que pierden.

La crisis y el ajuste estructural también han conducido a que se incrementen las diferencias sociales en casi todos los países con algunas excepciones, que son las de los países que no han seguido al pie de la letra las condiciones del ajuste neo-liberal.

En los Estados Unidos todos los indicadores muestran que desde los comienzos de los años 80 la brecha entre ricos y pobres se ha venido acentuando considerablemente, y esto continuó en los años 30, a pesar de que la economía empezó a recuperarse. Entre 1989 y 1993, mientras el 50\% de población de menor ingreso vió sus niveles de vida empeorar, el 50\% superior las mejoró. En 1993 la brecha existente entre ricos y pobres es un $12,4 \%$ mayor que la que existía em 1989. Entre 1979 y 1990 nos dice Edward N. Luttwak ${ }^{6}$ el número de activos que trabajan a tiempo completo

(6) Edward Luttwak "The Endangered American Dream "Simon and Schuster, 1993 y que no ganaban lo suficiente para hacer vivir una familia de 4 personas por encima del nivel de pobreza se habia multiplicado por dos, pasando de 7,8 a 14,4 millones. Y agrega, en 1980 los directores de empresas que figuraban en las listas de grandes sociedades establecidas por "Business Week" percebían en promedio $625 \mathrm{mil}$ dólares, 42 veces el salario medio de los obreros fabriles corrientes. Pero en 1991 estos ingresos de los directores habían aumentado a 2.466.000 dólares, 104 veces más que los salarios de los mismos obreros.

Por su parte Edmund Phelps, profesor de la Universidad de Columbia y uno de los grandes expertos norteamericanos en la economía política, señala que si bien en los Estados Unidos la tasa de desempleo es menor que en Europa, no hay que olvidar que el salario medio de los trabajadores no ha mejorado en los últimos 20 años, que el de los menos calificados ha bajado en los $25 \%$ y que entre estos últimos la tasa de desempleo pasó de $5 \%$ a comienzos de los años '70, a 12\% hoy dia. Parte de la población especialmente entre los jóvenes de las minorías étnicas, han salido del mercado de trabajo dedicándose al comercio de drogas y otros tráficos callejeros, lo que ha aumentado la criminalidad. En cierto modo esto constituye para ello su próprio "Estado Providencia", lo que hacer en las prisiones de ese país hay 1,5 millones de hombres en edad de trabajar, lo que representa el $1 \%$ de la fuerza de trabajo ${ }^{7}$.

En el caso de América Latina donde globalmente a comienzos de los años 90, el 39\% de los hogares se ubicaban bajo la línea de pobreza y en ciertos países como Bolivia, Brasil, Colombia, Guatemala y Honduras, se superaba ampliamente este porcentaje en términos de la población involucrada, los progresos de otros países para

(7) Entrevista a Edward Phels publicada en el diario “Le Monde”bajo la rúbrica "Les Grandes Entretiens du Monde” Junio de 1996 
disminuir la pobreza se han hecho más limitados desde 1994 como es el caso de Argentina, Costa Rica y México. En el caso de Argentina, donde se privilegió el control de la inflación el crecimiento económico fue acompañado de um incremento del desempleo que se atribuye fundamentalmente al proceso de reforma ${ }^{8}$. En el $2^{\mathrm{O}}$ semestre de 1997 tenía una tase de desocupación de más de 16\% que afectaba a más de 2 millones de personas. En Buenos Aires una de las ciudades más ricas de America Latina 150 mil personas viven como ocupantes ilegales en casas tomadas. El $46 \%$ de ellas son desempleadas. En Perú el supempleo y el desempleo alcanza hoy al $50 \%$ de la fuerza de trabajo.

Otros Estudios como el de la agencia Alemana de Prensa DPA 9 , indican que los trabajadores latinoamericanos de bajos ingresos alcanzan a cubrir mensualmente con su salario sólo el $51 \%$ de sus necesidades básicas, debiendo buscar en el sector económico informal lo que les falta para poder subsistir. En comparación con 1995 la situación empeoró en 1996, lo que explica la extensión de las protestas sociales que se han visto últimamente en Venezuela, México, Bolivia, Ecuador, El Salvador y Argentina.

En México, designado antes de la crisis de fines de 1994 como el modelo de la nueva política económica neo-liberal, sobre una población de 100 millones de personas, el 10\% controla el 70\% del ingreso nacional, mientras que el $90 \%$ restante se distribuye el $30 \%$ que resta. De 37 millones de activos, 21,5 millones no tienen trabajo fijo y de los 15,2 millones que perciben salario regular la inmensa mayoría gana menos de 3 dólares diarios. La Revista norteamerica FORBES publicó en Julio de este año la lista de los 15 multimillonarios mexicanos que se beneficiaron con las

(8) CEPAL "Panorama Social de América Latina en 1995", (9) Ver el Mercurio, 25 de Julio de 1996 privatizaciones fraudulentas de los últimos años. A fines de 1995, 24,6 mil millones de dólares de propiedad de mexicanos estaban depositados en los bancos norteamericanos, el doble que a fines de $1994^{10}$.

En el conjunto de América Latina entre 1991 y 1996 la economía regional creció en 3\%, la misma cifra de aumento en promedio de la pobreza, según un seminario del BID sobre Desarrollo Social que se celebró en Washington. De los 470 millones de latinoamericanos, 235 millones son pobre, el desempleo llegó a un promedio de 16,3 por ciento y el salario mínimo se depreció en 30 por ciento entre 1980 y 1996, destacan los estudios del BID.

También ponen de relieve que el 60 por ciento de los niños viven en hogares de extrema pobreza y que 20 millones trabajan en talleres clandestinos donde son explotados.

El 51,5 por ciento de los niños no terminan sus estudios primarios y los que lo hacen tardan en promedio diez años cuando se requieren sólo seis.

El BID advirtió igualmente de que el 41 por ciento de los pobres sufren grados de desnutrición que se traducen en una reducción del tamaño y el peso de sus hijos.

A nivel mundial el número de pobres aumenta en 25 millones cada año y actualmente la cuarta parte de la población mundial vive en la pobreza extrema.

Las bases de una nueva política para enfrentar las consecuencias de la globalización

En este nuevo contexto de un sistema internacional dominado por las tendencias hacia la globalización, el debilitamiento de los Estados Naciones, el domínio de las fuerzas del capital supranacional y la reducción de los hombres al

(10) Jaime Aviles, Redactor en Jefe del Periódico "La Jornada", artículo publicado en "Le Monde Diplomatique" de Agosto de 1996. 
nivel de consumidores ¿qué debería hacerse para recuperar la iniciativa y contribuir al establecimiento de un mundo menos desigual y más solidario?.

Lo primero que nos parece necesario afirmar es que no se debe, frente a las consecuencias sociales negativas de la globalización, pretender oponerse a ella mediante reacciones nacionalistas de tipo defensivo. Pensamos que ello sería utópico y se tiene todas las de perder. Pero tampoco se trata de aceptar ciegamente como un paquete todo lo que arrastra consigo actualmente la palabra globalización. Este es un proceso bastante avanzado, imposible de retrogradar totalmente en que es preciso discernir los aspectos positivos de los negativos y aceptando y apoyando los primeros debemos tratar de corregir los segundos mediante políticas que sólo muy parcialmente podrán ser nacionales, pero que en lo fundamental deben ser internacionales. Hay entonces que crear conciencia y juntar fuerzas para ello, y esto será una tarea ardua, difícil y larga a menos que, como es perfectamente posible ciertas crisis internacionales del sistema financiero que se vislumbran, aceleren el proceso de cambio.

La globalización de los mercados y dentro de ella la búsqueda de la competitividad en dichos mercados está llevando hoy día en todas partes a la disminución de los salarios reales, al desmantelamiento de los sistemas de protección social, al incremento brutal del desempleo junto con la precarización de las ocupaciones y el deterioro de las condiciones de trabajo. En la ideología dominante esto se considera indispensable para ser competitivos y simultáneamente se ve como aumentan por todas parte los salarios y beneficios de los ejecutivos de las empresas. Mientras más se grava el trabajo en las grandes empresas más sube el valor de las acciones y los salarios de los ejecutivos. Esto es inaceptable desde el punto de vista de la equidad y de las condiciones de un sistema democrático. No sólo debe ser denunciado con vigor sino debe ser corregido mediante sistemas impositivos o utilizando otros mecanismos. Hay aquí un plan de acción en que una política de desarrollo y progreso social tiene un gran trabajo por delante.

Pero también en la globalización actual, como vimos la lógica financeira se impone sobre la lógica de la economía real. El poder financeiro que se denomina "el mercado" se hace cada vez más autónomo frente a las sociedades y a la economía real e impone sus normas de rentabilidad a las empresas y a los Estados.

Desde comienzos de los años 90 las operaciones diarias en las bolsas internacionales se calculan en una cifra que supera largamente los mil doscientos billones de dólares. Una mínima parte corresponde a inversiones reales o se hace en función del comercio internacional de mercancías. El gran volumen está constituído por colocaciones netamente especulativas en los mercados de intereses, divisas y mercancias. Este comercio especulativo ha sido bautizado como un capitalismo de casino.

Ya a comienzos de los años 70 para evitar esta especulación y permitir a los gobiernos recuperar su autonomía en materia de políticas macro-económicas el economista James Tobin, premio Nobel de Economía, propuso imponer a las transacciones ligadas a los cambios monetarios con un impuesto de transferencia bastante moderado con el fin de desencentivar la especulación. Su idea fue calificada de irrealista. Ha sido retomada en varias ocasiones pero, siempre ha encontrado enemigos en los medios interesados en que no se lleve adelante.

En Octubre de 1995 un grupo de expertos y especialistas de la economía y de las finanzas internacionales, de la más alta calificación estudió 
a fondo esta idea a la luz del estado del conocimiento existente en materia de los movimientos de los capitales y de la experiencia de ciertos países y la encontró muy positiva. El proyecto recibió el apoyo de personalidades tan diversas como Jacques Delors (Presidente entonces de la Comisión Europa), de Boutros Boutros-Ghali (Secretario General de las Naciones Unidas) y de Barber Conable, Presidente del Banco Mundial de 1986 a 1991. Sin embargo, una conspiración del silencio le sigue rondando.

Esto demuestra la posible existencia de macanismos de control de la especulación financiera que tanta inestabilidad crea en las economías, si los gobiernos deciden enfrentar este problema. Aquí hay outra bandera de lucha que se deberá enarbolar como uno de los postulados básicos en el mundo globalizado actual. El poder aparentemente irresitible de los mercados financieros sólo existe por la actual sumisión de los gobiernos a estos mercados financieros. Como lo decia en febrero de 1996 en Davos, Hans Tietmeyer, el Presidente del Bundersbank "Los mercados financieros desempeñarán cada vez más el rol de gendarmes. Los políticos deben comprender que están en lo sucesivo bajo el control de los mercados financieros y no solamente de sus electores nacionales ${ }^{\prime \prime 1}$. Este verdadero trastocamiento de los valores democráticos es inaceptable y los gobiernos deberán reaccionar colectivamente frente a ello.

Una tercera bandera de lucha que se deberá profundizar y desarrollar es la de las nuevas relaciones entre la economía, la sociedad y el trabajo. Las nuevas formas de organización del trabajo productivo en las economías globalizadas están conduciendo rápidamente a una división de los trabajadores en un núcleo central cada vez más reducido de trabajadores permanentes a tiempo completo dotados de polivalencia profesional y de (11) Libro citado anteriormente de André Gorz (p. 36). movilidad. En torno a este núcleo gira una masa importante de trabajadores periféricos con una proporción significativa de precarios e intermitentes com horarios y salarios variables. A estos trabajadores periféricos se agrega una proporción cada vez más importante de trabajadores externos, es decir, prestatarios de servicios pretendidamente independientes, pagados por tarea, cuyos horarios de trabajo varían según las necesidades del momento. Estos independientes no están protegidos ni por la legislación del trabajo ni por las prestaciones sociales y están expuestos a todas las vicisitudes de la coyuntura. En 1993 las mayores 500 empresas norteamericanas no empleaban sino 10\% de asalariados permanentes a tiempo completo.

La externalización permite al capitalismo restablecer para una parte creciente de los activos las condiciones sociales de comienzos del siglo XIX. Ello conduce a un gran número de trabajadores, para poder sobrevivir, a un aumento considerable y extenuante de su jornada de trabajo.

Por outro lado como lo han señalado numerosas investigaciones la creencia que la aceleración del crecimiento y la recuperación de las crisis creará un gran número de nuevos empleos se revela cada vez más falsa. La automatización creciente de los sistemas de producción y de los servicios a fin de hacer a las empresas más competitivas están haciendo desaparecer gran número de empleos y aumentado en todas parte la cesantía. Más de 800 millones de activos estaban desempleados o subempleados en el mundo en 1994 según la Organización Internacional del Trabajo ${ }^{12}$.

Todo esto hace que el tipo de sociedad en la cual los hombres podrán esperar tener un porvenir y una seguridad estables mediante un trabajo asalariado, crecientemente remunerado, está desapareciendo rápidamente. Y la educación,

(12) Ver particularmente Jeremy Rifkin "The End of Work", Ediciones G.P. Putnam's Sons, New York, 1995. Existe traducción al castellano. 
aún altamente calificada, ya no es una garantía suficiente para asegurar dicho provenir.

La economia de la sociedad capitalista globalizada ya no está en condiciones de asegurar a todos la plenitud de los derechos económicos mediante un ingreso suficiente ligado al trabajo asalariado y los derechos sociales y de protección derivados de dicho trabajo. Algunos hablan ya que en el próximo siglo estaremos en la sociedad donde el $20 \%$ más rico se bastará a si mismo ${ }^{13}$. No se necesitará más mano de obra. Un quinto de los que buscan empleo bastará para producir todas las mercaderías y realizar todas las prestaciones de servicios de alto valor que puede ofrecer la sociedad mundial. Estos dos décimos se la población participarán así activamente en la vida social, los ingresos y el consumo en los diferentes países. El resto tendrá que sobrevivir como pueda.

Otros hablan de un crecimiento por regiones enclaves ${ }^{14}$. Un eminente especialista japonés del nuevo modelo de desarrollo capitalista hablando de China, India, Mạlasia, México y Brasil, considera que el capitalismo impulsa en la era post-industrial "zonas económicas especiales"cuyo ingreso será diez o veinte veces más alto que el de los habitantes del resto del país. Estas zonas tendrán que ser defendidas contra la inmigración no del exterior, sino que de su próprio país, de los campesinos sin tierras expulsados por el éxodo rural.

El modelo de industrialización que permitió el desarrollo de Occidente y del Japón y que facilitó la urbanización convirtiendo en asalariados a las masas rurales ya no existe más. Desaparece aún en China donde se ha hecho obsoleta y

(13) Hans-Peter Martin Y Harald Schumann "La Piège de la Mondialisation", Ediciones Acte Sud, París, 1997.

(14) Keinichi Ohmae “De L’Etat Nation aux Etats Région”, Dunod, Paris, 1996. no competitiva la industria tradicional que hacía vivir antes de la época del "comunismo de mercado" a 110 millones de asalariados a los que aseguraba el mínimo vital en materia de comida, alojamiento y servicios ${ }^{15}$.

Ante esta nueva situación será pues necesario buscar las formas de superar la sociedad salarial en que el rol del individuo en la sociedad estaba fundamentalmente determinado por su inserción en el trabajo remunerado. Este será sin duda el gran desafío del siglo XXI y un elemento esencial de toda política de equidad.

Las relaciones sociales, los lazos de cooperación, el sentido de cada vida serán producidos en el futuro principalmente por actividades que no estarán dirigidas a la valorización del capital. El tiempo destinado al trabajo productivo dejará de ser para la mayoria el tiempo social dominante.

¿Cómo enfrentar esta nueva situación? La reflexión apenas comienza a este respecto. El desafío es sustraer al poder del mercado, del capital y de la economía los campos de actividad que se abren por el tiempo liberado del trabajo productivo. Y al mismo tiempo que cada ser humano reciba un ingreso que le permita cubrir sus necesidades esenciales y no tener que, para sobrevivir, la necesidad de plegarse a la desvalorización de su trabajo que resulta de las nuevas condiciones del capital. Varias ideas se han adelantado a este respecto ${ }^{16}$ : garantizar a todos un ingreso suficiente de base, un mínimo vital, que no les oblique a tener que emplearse por salarios de miseria en cualquier condición que puede o no estar ligado a la obligación de un trabajo social de interés colectivo; combinar la redistribución del trabajo con el control individual o colectivo del tiempo libre; favorecer la creación de nuevas modalidades de cooperación

(15) André Gorz, obra citada, página 45.

(16) Ver particularmente los livros de André Gorz y de Jeremy Rifkin. 
y de intercambio en las cuales la cohesión y los lazos sociales se creen al margen del sistema de salarios, etc.

Hay aquí todo un campo de reflexión y de acción en el que se tiene una gran tarea por delante.

Además de estos tres grandes campos de acción que se dan en el marco de la actual globalización de orientación neoliberal o neo-conservadora y que se debe luchar por modificar significativamente, a saber: la distribución del ingreso en el seno de la nueva economía en favor del trabajo y no en su desmedro como ocurre hoy día, la regulación de la libre circulación financiera y la búsqueda de nuevas relaciones entre la economia, la sociedad y el trabajo en un mundo en que el trabajo asalariado se ve cada vez más marginalizado y desvalorizado, existen muchos otros aspectos en que una nueva política tiene sin duda una gran importancia.

Una de ellas es la búsqueda de un nuevo equilibro entre la economía, la cultura y la política. La idea de que el aumento del ingreso y de la riqueza económica es la clave de todas las formas de progreso, no solamente de comodidad material, sino también de la educación, de la salud, de la vivienda, de las condiciones de vida y de la cultura, debe ser profundamente revisada. Si el crecimiento económico tiene una contrapartida de destrucción de los recursos naturales y de empeoramiento del medio ambiente en que viven los hombres ello no es aceptable y comienza a ser cada vez menos aceptado. Por outro lado hay que combatir la creencia de que la economía está naturalmente orientada al progreso de la cultura. Hay que dejar de aceptar el hecho de la subordinación creciente de la cultura y de la política a la economía, como si este fuera un hecho natural derivado de las necesidades de la propria sociedad. De medio la economía se ha convertido en fin. No hay más que observar en la vida de todos los días el hecho de la reducción de la calidad a la cantidad, el fetichismo de las cifras que caracteriza la pasión por el dinero y que se extiende al conjunto de indicadores de la calidad de vida, el lugar cada vez más exclusivo del trabajo remunerado como elemento de acceso a una identidad y a un status social ${ }^{17}$.

Considerando las amenazas que pesan sobre la cultura y sobre el medio ambiente y el domínio del dinero sobre la sociedad, hay que rechazar el imperio del "laisser-faire". No se puede aceptar que sean los "libres" consumidores, a menudo manipulados por la publicidad, los que orientan toda la producción y que el respeto de la democracia debe conducir a los poderes públicos a no intervenir. Porque a pesar de lo se dice la política interviene constantemente, ya sea para orientar la utilización del suelo urbano o rural, lo que determina un cierto tipo de urbanismo o de ruralismo, ya sea por las inversiones en infraestructura de transportes y comunicaciones que favorecen o al auto particular o al transporte colectivo, ya sea dando un marco jurídico a los sistemas audiovisuales, etc. El papel del Estado y de los servicios públicos, son esenciales en la orientación de la sociedad en todos estos aspectos y es aquí donde un debate democrático debe imponerse. No se puede aceptar, por outra parte, que con el pretexto de hacer estos servicios más eficientes se impongan a veces criterios de racionalidad mercantil de corto plazo o la voluntad de producir economías.

La destrucción del medio ambiente bajo el efecto de un desarrollo incontrolado de actividades económicas manifiesta con evidencia que la naturaleza no puede ser como tratada una mercadería.

(17) Bernard Perret y Guy Roustang "L'Economie contre la Societé", Edition Le Seuil, Paris 1993. 
Independientemente de los problemas del medio ambiente existen numerosos otros bienes y servicios en los cuales la producción y la distribución no pueden ser reguladas por el mercado: la educación, la salud, la seguridad ciudadana. En todos estos campos el simple cálculo económico de rentabilidad no puede ser suficiente para determinar los que se hace o lo que no se hace y los procedimientos de evaluación deben considerar muchas otras variables sociales, culturales y ambientales.

Este es outro campo de acción en que una política y critérios de orientación adecuados deben ser rápidamente elaborados para una nueva sociedad adaptada a los tiempos que vivimos. 